\title{
Differences in Medicare Expenditures During the Last 3 Years of Life
}

\author{
Lisa R. Shugarman, PhD, Diane E. Campbell, PhD, Chloe E. Bird, PhD, Jon Gabel, MA, \\ Thomas A. Louis, PhD, Joanne Lynn, MD, MS
}

OBJECTIVE: To examine age, gender, race, and area income differences in Medicare expenditures in the 3 years before death.

DESIGN: Cross-sectional study.

PARTICIPANTS: A random sample of aged Medicare beneficiaries who died 1996 to $1999, N=241,047$.

MEASURES: We estimate differences in mean Medicare expenditures by year before death and by age, gender, race, and area income, adjusting for comorbidities and Medicaid enrollment.

RESULTS: Expenditures for blacks are lower in the second and third years before death and are not significantly different from whites in the last year of life (LYOL) (y3 = 70\%, $P<.0001$; y2 $=82 \%, P<.0001 ;$ LYOL $=119 \%, P=.098)$. Differences in expenditures between decedents with area incomes over $\$ 35,000$ compared to under $\$ 20,000$ attenuate by the LYOL (y3 = 116\%, $P<.0001 ;$ y2 $=107 \%, P<.0001 ;$ LYOL $=96 \%$, $P<.0001)$. Expenditure patterns for women versus men vary by age. Among the younger cohorts (68 to 74 and 75 to 79 ), expenditures are higher for women in all 3 years before death. This difference attenuates among older cohorts; in the oldest cohort (90+), expenditures for men exceed those for women by $11 \%$ in the LYOL $(P<.0001)$. Older beneficiaries have higher expenditures in the second and third years before death but lower expenditures in the LYOL. On average, the youngest cohort expended $\$ 8,017$ more in the LYOL relative to the oldest cohort, whereas in the third year before death, the oldest cohort's expenditures were $\mathbf{\$ 5 , 2 7 0}$ more than those for the youngest cohort $(P<.0001)$.

CONCLUSIONS: Age-associated differences in aggregate Medicare payments for end-of-life care are more substantial than other differences. The fact that other differences attenuate in the LYOL may reflect having overcome barriers to health care, or reflect an effective ceiling on the opportunities to provide services for persons with overwhelming illness.

An earlier version of this paper was presented at the 2002 Annual Meeting of the Academy for Health Services Research and Health Policy in Washington, DC.

Received from RAND Health (LRS, CEB), Santa Monica, Calif; Medical Outcomes Research and Evaluation Services (DEC), Thetford, Vt; Health Research and Education Trust (JG), Washington, DC; Department of Biostatistics (TAL), Johns Hopkins Bloomberg School of Public Health, Baltimore, Md; RAND Health (JL), Arlington, Va; and Washington Home Center for Palliative Care Studies (JL), Washington, DC.

Address correspondence and requests for reprints to Dr. Shugarman: Associate Health Policy Researcher, RAND, 1700 Main Street, PO Box 2138, Santa Monica, CA 90407-2138 (e-mail: Lisa_Shugarman@rand.org).
KEY WORDS: end of life; gender; Medicare; race; socioeconomic status.

J GEN INTERN MED 2004;19:127-135.

$\mathrm{D}$ ue to advances in health care and in public health interventions, American adults can expect to live well into their ninth decade. Median life expectancy at birth has reached 79.5 years for women and 73.8 years for men. ${ }^{1}$ As a consequence, financing of end-of-life health care largely occurs within Medicare. Services and costs near the end of life have become an important focus of policy and practice. Of the 2.3 million Americans who died in 1997, roughly 2 million (86\%) were Medicare beneficiaries. ${ }^{2}$ For 2 decades, care in the last year of life has represented over one quarter of Medicare's budget. ${ }^{2,3}$ By default, Medicare's financing policies constitute America's public policy on the financing of end-of-life care.

Many studies and reports have documented major disparities in receipt of health care across the lifespan. ${ }^{4-9}$ Gender, race, and socioeconomic characteristics mark substantial differences in use of medical care by the elderly and within Medicare specifically. ${ }^{10-23}$ However, few studies have examined disparities at the end of life.

We examine age, gender, race, and area income differences in expenditures among Medicare beneficiaries in the 3 years prior to death. Our study expands the framework of end-of-life care studies from the last 12 months of life to the last 3 years of life. Furthermore, while much prior research on end-of-life care relies on data that is 10 to 20 years old ${ }^{3,24-26}$ or comes from a limited geographic population, ${ }^{27,28}$ this study uses more recent national, population-based data (1993 through 1999).

\section{METHODS}

\section{Design}

We used linear regression, adjusting for comorbidities, Medicaid enrollment, urban/rural regions, and local health service supply factors to estimate differences in mean total Medicare expenditures in each of the last 3 years of life by age, gender, race, and area income. Data sources included Medicare's 5\% sample denominator and claims files for 7 years (1993 through 1999), the Area Resource File for supply variables linked to claims by state and county of beneficiary residence, and the 1990 Census for area income linked to claims by ZIP code of beneficiary residence in their last year of life. This project was reviewed and approved by the RAND Corporation's institutional review board. Patient consent was not required because administrative 
claims records were obtained for decedents only. Appropriate data safeguarding plans were established and put in place prior to the start of data analysis.

\section{Setting and Participants}

From the 5\% sample of aged (65+) Medicare beneficiaries who died between 1996 and $1999(N=265,170)$, we excluded end-stage renal disease (ESRD) patients, those eligible for Medicare because of disability, and those in managed care $(2.2 \%)$. We further excluded those who were not continuously enrolled in both Medicare Part A (Hospital Insurance) and Part B (Supplemental Medical Insurance) for 36 months prior to their death between January 1, 1996 and December 31, 1999 (5.5\%). Because the "other" race category comprised a small proportion of our sample (2.0\%), we excluded them, retaining only those beneficiaries identified as white or black. Our resulting analytic sample included decedents age 68 and older $(N=241,047)$.

\section{Outcome Measures}

The principal outcome measure was total annual Medicare expenditures for each of 3 years prior to death. Medicare expenditures were the sum of inflation-adjusted (to 1999 dollars) Medicare program payments to providers for each of 6 service types: inpatient, outpatient, skilled nursing, home health, hospice, and physician. Deductibles, coinsurance, durable medical equipment, payment by other insurance, and out-of-pocket expenses were not included.

\section{Individual Attributes}

Our individual attributes (covariate measures) included age, gender, race, Medicaid enrollment, area income, rural/ urban setting, comorbidities, hospital beds, and physician supply. We derived age, gender, race, and Medicaid enrollment from the Medicare Denominator files. Age at death was calculated from dates of birth and death and collapsed into 5 cohorts: 68 to 74,75 to 79,80 to 84,85 to 89 , and 90 and older. We categorized race as white or black. Medicaid enrollment reflects any state buy-in to Medicare during the last year of life.

Income in the last part of life is often misleading because so much of available funds is in savings or other nonincome assets. In order to capture socio-economic resources, we used ZIP code-level area income, which reflects differences across neighborhoods in both income and assets. Individual socioeconomic status will be generally associated with area income, with people living in wealthy areas generally having more assets and higher socioeconomic status than people living in poorer areas. ${ }^{29,30} \mathrm{We}$ linked the Medicare Denominator file with ZIP code level census data and obtained the median household income for the beneficiaries' ZIP codes of residence during their last year of life. We defined 3 area income categories: < \$20,000, $\$ 20,000$ to $\$ 34,999$, and $\geq \$ 35,000$. To categorize the county of residence as metropolitan, small urban, or rural, we linked Urban Influence Codes from the Area Resource File to the Denominator file by state and county of residence. ${ }^{31}$

In order to control for case mix, we developed a count of comorbidities present in the claims for each beneficiary's last 3 years, adapting the method developed by Charlson et al. ${ }^{32}$ We screened all claims for mention of 16 comorbid conditions: myocardial infarction, congestive heart failure, peripheral vascular disease, cerebrovascular disease, dementia, chronic obstructive pulmonary disease, rheumatoid arthritis, peptic ulcers, chronic liver disease and cirrhosis, diabetes, hemiplegia, quadriplegia, renal failure, malignant neoplasms, metastatic cancer, and AIDS (associated ICD9-CM codes are available from the authors upon request). We included the number of comorbidities ( 1 to 16 as a continuous variable) as a control for burden of illness. We also controlled for 2 county level supply factors obtained by linking to the Area Resource File: number of hospital beds and total number of physicians, both as the rate per 1,000 people 65 and older.

\section{Statistical Analysis}

We analyzed data using SAS statistical software, version 8.0. ${ }^{33}$ Using analysis of variance for unadjusted expenditures, we described differences by gender, race, age, and area income categories within and across each of the last 3 years of life. Due to large sample size, almost all pairwise comparisons were statistically significant at $P<.0001$.

We also estimated mean Medicare program expenditures by age, gender, race, and area income with multivariable regression equations for each of the last 3 years of life, estimating both direct effects of the primary sociodemographic characteristics and interactions, controlling for Medicaid enrollment, comorbidities, metropolitan/small urban/rural county residence, and local supply factors. We tested both first- and second-order interaction terms in the model, but only first-order interactions are presented in this paper. Second-order interactions did not improve the models sufficiently to warrant their inclusion in the final model.

For multivariable analyses, we used the log-transformation of total expenditures for each of the last 3 years of life, adjusting zero expenditures in any year to $\$ 1$. We evaluated these models by using the $\chi^{2}$-statistic to test the statistical significance of each individual variable and $F$-statistics to test the joint significance of each direct effect and its associated interaction term. If the coefficients on the direct effect and the interaction were separately and jointly significant, we concluded that the interaction was important to our understanding of differences in expenditures at the end of life. We report the $r^{2}$ statistic for each of the 3 models representing the relationship between sociodemographic characteristics and Medicare expenditures in each of the last 3 years of life. We subsequently used the Duan adjustment to produce the exponentiated parameter estimates in the original dollar scale. ${ }^{34}$

To illustrate differences in expenditures between genders, race, area income groups, and age cohorts, we 
calculated ratios of differences in the regression-adjusted mean expenditures for age, race, gender, and area income categories for each of the last 3 years of life, controlling for Medicaid enrollment, urban setting, comorbidities, hospital bed, and physician supply. The ratios used the predicted mean expenditure for each level of the characteristic of interest or interaction (e.g., race and age), holding all other variables in the model constant. We compared blacks to whites by age, women to men by age, higher area incomes to those under $\$ 20,000$, and older cohorts to the youngest (age 68 to 74). A ratio of 1.0 indicates no difference in expenditures.

The research underlying this article was completed with support from the Medicare Payment Advisory Commission. The findings, statements, and views expressed are those of the authors and do not necessarily represent those of the Commission. In addition, this work was completed with support from the Agency for Health Research and Quality (Grant \#7R01HS10561-02), the National Institute on Aging (Grant \#1R03AG20344-01), the Fan Fox-Leslie Samuels Foundation, and The Washington Home Center for Palliative Care Studies.

\section{RESULTS}

Of the 241,047 Medicare decedents in our sample, roughly $20 \%$ fall in each of 5 age categories; the mean age at death is 82.8 years $( \pm 7.7$ ) (Table 1$)$. The sample is approximately $58 \%$ female and $8 \%$ black. About one quarter reside in areas with a median household income of more than \$35,000; approximately $20 \%$ reside in areas with median household income less than $\$ 20,000$. About $24 \%$ of the sample is Medicaid eligible, $72 \%$ reside in metropolitan areas, and $15 \%$ reside in rural areas. These characteristics vary by age at death. The older cohorts are disproportionately female and white and are slightly more likely to reside in areas with a median income of more than $\$ 35,000$.

As shown in Table 2, Medicare expenditures (unadjusted) increase dramatically in the last year of life. The mean total Medicare expenditures in the last year of life approach $\$ 24,700$, while the mean total Medicare expenditures in years 2 and 3 before death are less than $\$ 10,000$ per year. Median expenditures are much lower than mean expenditures, illustrating the influence of high-cost cases on the distribution. Less than one percent $(0.3 \%)$ of decedents had zero expenditures in their last year of life; approximately $4.7 \%$ and $6.5 \%$ had zero expenditures in their second and third years before death, respectively (data not shown).

In the second and third years before death, women's unadjusted Medicare expenditures exceed those of men; however, men's expenditures are higher than women's in the last year of life. Expenditures for blacks as compared to whites are consistently higher across all 3 years before death. Medicare beneficiaries residing in areas with a median household income above $\$ 35,000$ have higher expenditures than beneficiaries residing in areas with lower median incomes.

Medicare expenditures during the last year of life decrease with age, and the differences between groups are larger with each successive age cohort. Differences in expenditures by age cohort in the second and third year before death are smaller.

For each of 3 years before death, Table 3 reports linear effects of gender, race, area income, and age on the log of total Medicare expenditures after controlling for urban/ nonurban metropolitan/rural county residence, Medicaid enrollment, comorbidities, and supply factors. Positive

Table 1. Descriptive Characteristics of Study Sample*

\begin{tabular}{|c|c|c|c|c|c|c|}
\hline \multirow[b]{2}{*}{ Variable } & \multirow[b]{2}{*}{$\begin{array}{c}\text { All Ages } \\
(N=241,047)\end{array}$} & \multicolumn{5}{|c|}{ Age at Death } \\
\hline & & $\begin{array}{c}68 \text { to } 74 \\
(N=44,986)\end{array}$ & $\begin{array}{c}75 \text { to } 79 \\
(N=46,981)\end{array}$ & $\begin{array}{c}80 \text { to } 84 \\
(N=52,746)\end{array}$ & $\begin{array}{c}85 \text { to } 89 \\
(N=48,773)\end{array}$ & $\begin{array}{c}90+ \\
(N=47,561)\end{array}$ \\
\hline White female, \% & 52.8 & 40.8 & 44.4 & 50.6 & 58.6 & 69.3 \\
\hline White male, \% & 39.2 & 49.4 & 46.9 & 42.0 & 34.4 & 23.6 \\
\hline Black female, \% & 4.7 & 4.7 & 4.5 & 4.3 & 4.5 & 5.4 \\
\hline Black male, \% & 3.3 & 5.1 & 4.3 & 3.1 & 2.6 & 1.8 \\
\hline \multicolumn{7}{|l|}{ Area income, \% } \\
\hline$<\$ 20,000$ & 19.6 & 20.9 & 20.1 & 19.2 & 19.0 & 18.6 \\
\hline$\$ 20,000-\$ 35,000$ & 55.1 & 56.4 & 55.6 & 55.4 & 54.6 & 53.6 \\
\hline$>\$ 35,000$ & 25.3 & 22.7 & 24.2 & 25.4 & 26.4 & 27.8 \\
\hline Medicaid enrollment, \% & 23.7 & 19.0 & 19.2 & 20.8 & 25.9 & 33.6 \\
\hline \multicolumn{7}{|l|}{ Region, \% } \\
\hline Metropolitan & 71.8 & 70.5 & 71.9 & 71.8 & 72.4 & 72.4 \\
\hline Small urban & 13.4 & 14.0 & 13.5 & 13.4 & 13.0 & 12.9 \\
\hline Rural & 14.8 & 15.5 & 14.6 & 14.8 & 14.6 & 14.7 \\
\hline Mean comorbidities $( \pm \mathrm{SD})^{\dagger}$ & $3.4(1.9)$ & $3.5(2.0)$ & $3.6(2.0)$ & 3.5 (1.9) & $3.4(1.8)$ & $3.0(1.7)$ \\
\hline
\end{tabular}

* All relationships are statistically significant at $\mathrm{P}<.0001$.

${ }^{\dagger}$ Range: $O$ to 16 . SD, standard deviation. 
Table 2. Unadjusted Mean and Median Medicare Expenditures for the Last 3 Years of Life*

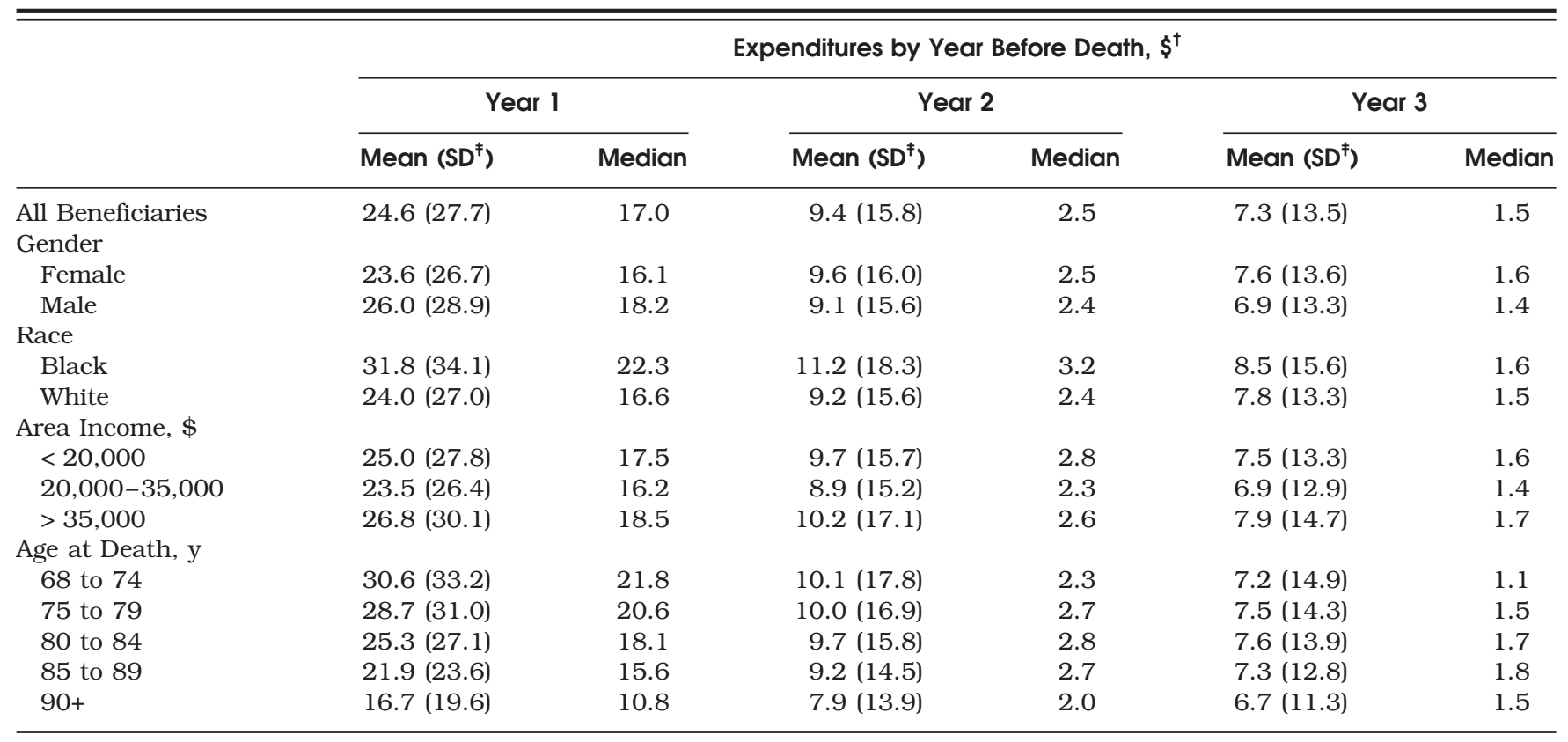

* Group differences in expenditures are statistically significant at $\mathrm{P}<.0001$.

${ }^{\dagger}$ In thousands per beneficiary.

${ }^{\ddagger} \mathrm{SD}$, standard deviation.

coefficients indicate characteristics associated with higher Medicare expenditures relative to the reference group.

In the adjusted model, women's total mean expenditures are higher than men's for each of the last 3 years of life, although the coefficient on the main effect is smaller for the last year of life than for expenditures 2 and 3 years before death, suggesting the difference in expenditures diminishes in the last year of life. Black women's expenditures

Table 3. Multiple Linear Regression Results on the Log of Medicare Expenditures, by Year Before Death**‡

\begin{tabular}{|c|c|c|c|c|c|c|}
\hline & \multicolumn{6}{|c|}{ Year Before Death } \\
\hline & \multicolumn{2}{|c|}{ Year 1 (Last Year) } & \multicolumn{2}{|c|}{ Year 2} & \multicolumn{2}{|c|}{ Year 3} \\
\hline Intercept & $7.85(0.012)$ & $<.0001$ & $5.24(0.016)$ & $<.0001$ & $5.22(0.020)$ & $<.0001$ \\
\hline Female & $0.30(0.013)$ & $<.0001$ & $0.46(0.019)$ & $<.0001$ & $0.57(0.023)$ & $<.0001$ \\
\hline Income $>\$ 35,000$ & $-0.05(0.009)$ & $<.0001$ & $0.07(0.014)$ & $<.0001$ & $0.15(0.017)$ & $<.0001$ \\
\hline Age 75 to 79 & $-0.01(0.013)$ & .27 & $0.13(0.019)$ & $<.0001$ & $0.34(0.023)$ & $<.0001$ \\
\hline Age 80 to 84 & $-0.02(0.013)$ & .07 & $0.25(0.019)$ & $<.0001$ & $0.55(0.023)$ & $<.0001$ \\
\hline Age 85 to 89 & $-0.06(0.014)$ & $<.0001$ & $0.33(0.020)$ & $<.0001$ & $0.66(0.024)$ & $<.0001$ \\
\hline Age $90+$ & $-0.16(0.015)$ & $<.0001$ & $0.37(0.023)$ & $<.0001$ & $0.64(0.027)$ & $<.0001$ \\
\hline Female* Age 75 to 79 & $-0.09(0.018)$ & $<.0001$ & $-0.07(0.026)$ & .011 & $-0.16(0.032)$ & $<.0001$ \\
\hline Black* Age 75 to 79 & $0.09(0.031)$ & .004 & $0.11(0.045)$ & .0129 & $-0.10(0.055)$ & .08 \\
\hline Black* Age 80 to 84 & $0.19(0.031)$ & $<.0001$ & $0.14(0.046)$ & .0023 & $0.06(0.056)$ & .29 \\
\hline Black* Age 85 to 89 & $0.28(0.032)$ & $<.0001$ & $0.20(0.048)$ & $<.0001$ & $0.03(0.058)$ & .56 \\
\hline Black* Age 90+ & $0.42(0.033)$ & $<.0001$ & $0.31(0.048)$ & $<.0001$ & $0.23(0.059)$ & $<.0001$ \\
\hline$r^{2}$ & 0.31 & & 0.07 & & 0.06 & \\
\hline
\end{tabular}

* The relationship between the variables of interest and the log of Medicare expenditures are estimated using least squares regression; coefficients, standard errors (SE), and P values are presented.

† The omitted category for area income is < \$20,000; the omitted category for age is 68 to 74 .

* These models controlled for any Medicaid use in the LYOL, comorbidities, urban/nonurban metropolitan/rural region of residence, the number of hospital beds per 1,000 population over 65, and the number of physicians per 1,000 population over 65 . 
appear to be higher than white women's expenditures in years 2 and 3 before death; however, this effect disappears in the last year of life. Additionally, age appears to modify the effect of gender on the log of expenditures; in each year before death, the difference in expenditures between men and women decreases as the age of the cohort increases. The difference in expenditures declines with older decedent cohorts; among those 85 to 89 , women's and men's expenditures in their last year of life are not statistically different.

After adjusting for other important characteristics, expenditures in years 2 and 3 before death are higher among older cohorts when compared to the youngest cohort (68 to 74). In the last year of life, this pattern of expenditures reverses; older cohorts have progressively lower expenditures. Expenditures for the 2 oldest age cohorts (85 to 89 and 90+) are significantly lower than those for the youngest age cohort.

On average, expenditures for blacks are lower than those for whites in the second and third year before death; however, in the last year of life, expenditures by race overall are not statistically different. The effect of age on the log of Medicare expenditures is significantly modified by race among older cohorts. In the third year before death, expenditures for blacks are moderately higher than for whites age $90+$. In the second year before death, we find large differences in expenditures with more spent on blacks. This difference increases with each age cohort. In the last year of life, while average expenditures are smaller for older cohorts relative to the youngest cohort, expenditures for older blacks (85 to 89 and $90+$ ) are still larger relative to the youngest decedent cohort.
Expenditures in years 2 and 3 before death are higher on average for those residing in areas with the highest median household income, as compared to those in areas with the lowest income. Mean expenditures for those in the wealthiest areas are 16\% higher in the third year before death $(P<.0001)$ and $7 \%$ higher in the second year before death $(P<.0001)$. The pattern of differences in expenditures between the highest and the lowest income areas narrows and reverses in the last year of life; expenditures for beneficiaries residing in the lowest income areas are $4 \%$ higher than for those residing in the highest income areas $(P<.0001)$ (data not shown). The variance explained by the regression models varies by year before death. The largest variance explanation, represented by the $r^{2}$ statistic, comes from the last year of life (31\%). The larger $r^{2}$ value in the last year of life suggests that personal characteristics have greater influence on use of Medicare services in the last 12 months of life than in prior years; other factors not included in the model may be more important in understanding expenditures in the years prior to the last year of life.

Figure 1 presents the ratios of regression-adjusted mean Medicare expenditures by age cohort and year before death. Expenditures in years 2 and 3 before death are higher for older decedents. In the last year of life, this pattern is reversed: expenditures for the age 85 to 89 decedent cohort are $17 \%$ lower $(P<.0001)$ than those for the youngest cohort, and expenditures for the age 90 and older decedent cohort are $31 \%$ lower $(P<.0001)$.

Figure 2 presents the ratios of regression-adjusted mean Medicare expenditures by gender and age cohort. Expenditures for women are higher than for men overall;

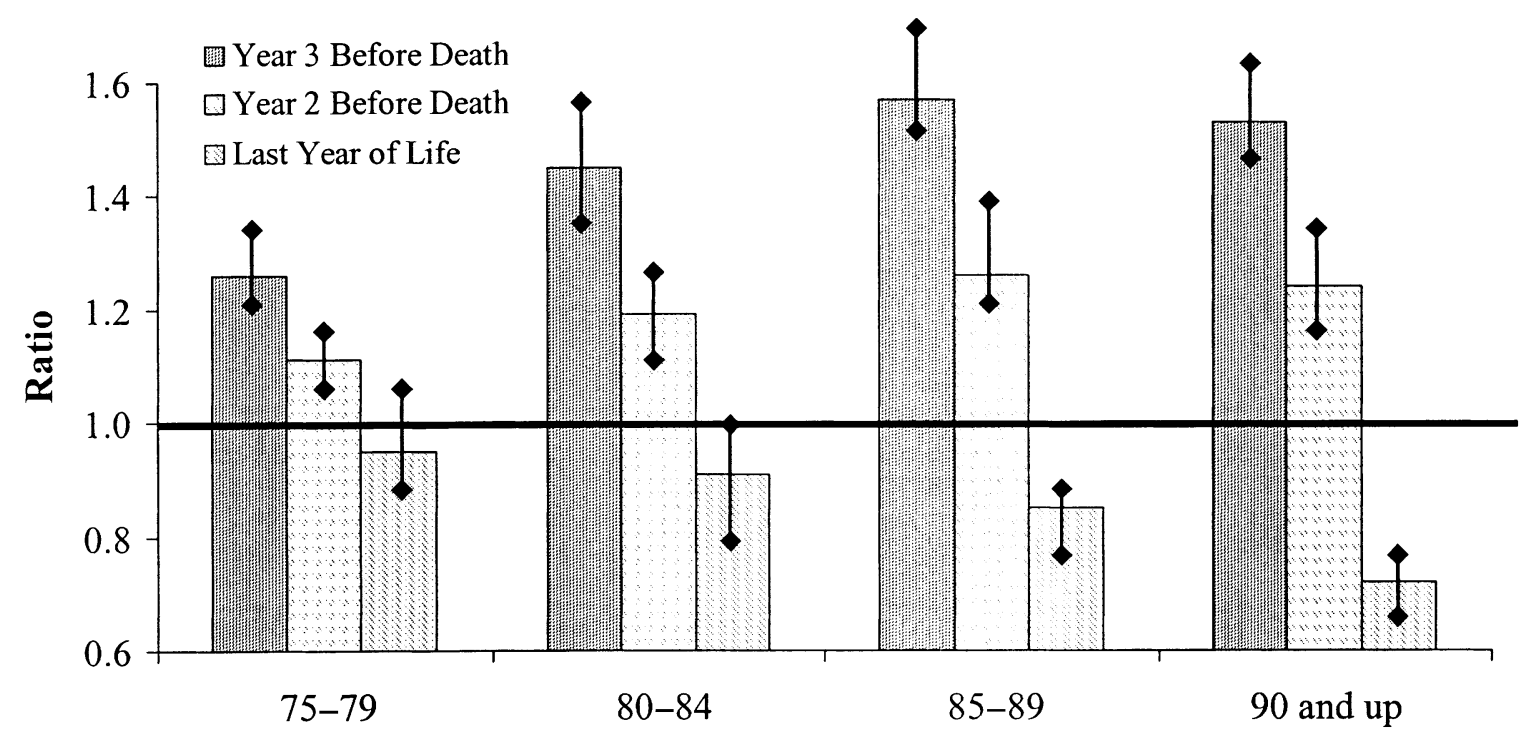

Age at Death

FIGURE 1. Ratio of regression-adjusted mean Medicare spending, in the last 3 years of life, by age at death. ${ }^{* \dagger}$

* Reference group for all ratios is the 68 to 74 age cohort. Regression-adjusted means were calculated for each beneficiary characteristic, controlling for other characteristics. Ratios were calculated by dividing mean expenditures for older cohorts by mean expenditures for the 68 to 74 age cohort. The bar in the figure is set at 1.0, reflecting no difference in expenditures.

${ }^{\dagger}$ Ninety-five percent of confidence intervals presented for each ratio. 


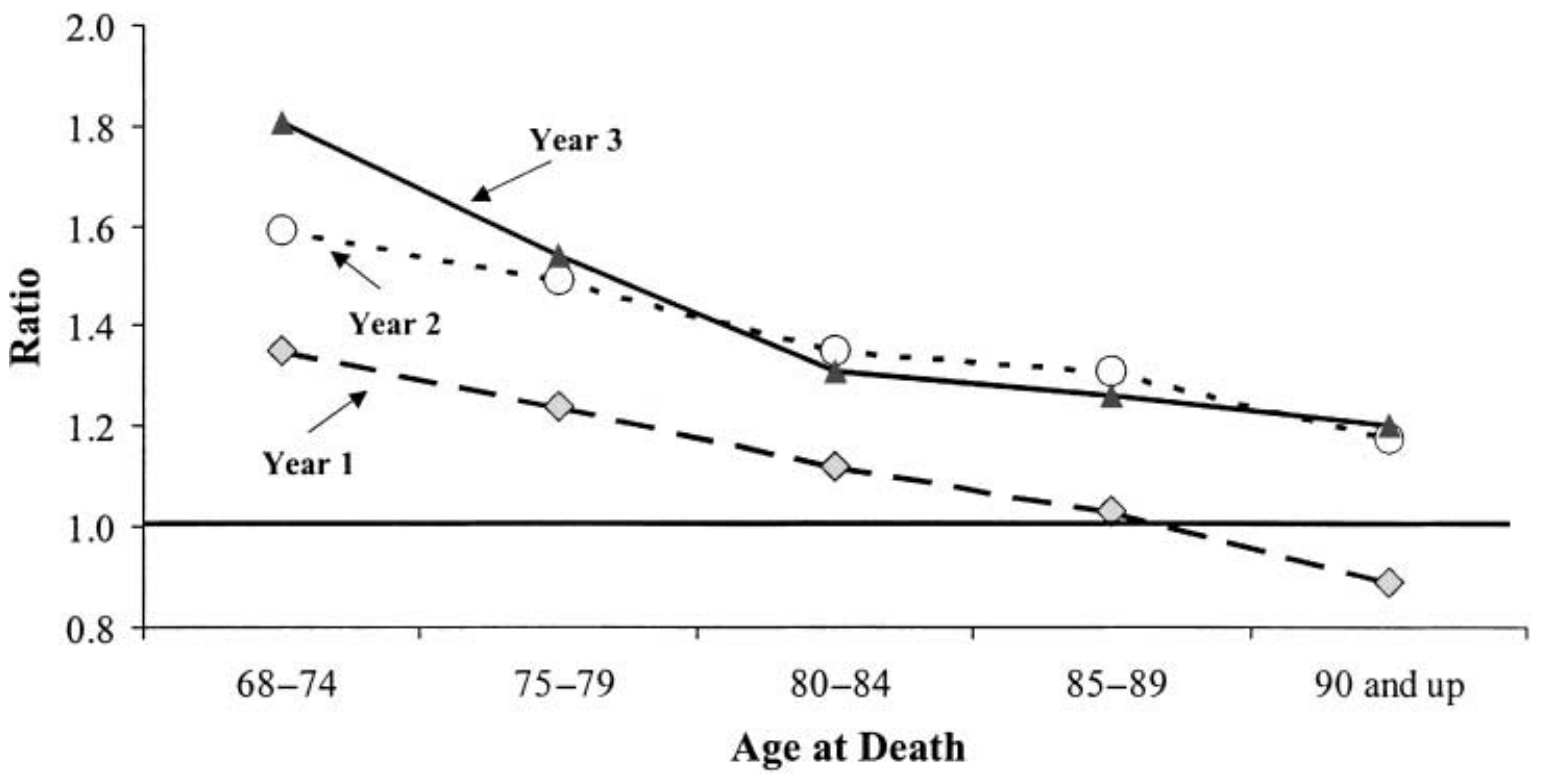

FIGURE 2. Ratio of regression-adjusted mean Medicare expenditures for women as compared to men in the last 3 years of life, by age at death. ${ }^{*}$

* Regression-adjusted means were calculated for each beneficiary characteristic, controlling for other characteristics. Ratios calculated by dividing mean expenditures for women by mean expenditures for men within each age cohort. The bar in the figure is set at a ratio of 1.0, reflecting no difference in expenditures.

${ }^{\dagger}$ Ratios are statistically significant at $P<.01$, with the exception of the ratio of expenditures for the 85 to 89 age cohort, in the last year of life ( $95 \%$ confidence internal $(\mathrm{Cl}) 1.00$ to 1.11$)$.

however, the ratio of expenditures for women and men partially reverses in the last year of life. In years 2 and 3 before death, expenditures are consistently higher for women than for men, although the effect is smaller among the older decedent cohorts. In the last year of life, expenditures for women are higher than for men in the 3 youngest decedent cohorts. However, the ratio of expenditures for men and women age 85 to 89 is very close to 1.0. Among those age 90 and older at death, expenditures are approximately $11 \%$ higher for men than for women.

Figure 3 presents the ratios of regression-adjusted mean Medicare expenditures by race and age group. Expenditures for blacks were lower than those for whites in years 2 and 3 before death; however, the differences were largest in the younger cohorts and not significantly different among the oldest decedent cohorts. In the last year of life, the ratio of expenditures for blacks to whites is reversed; more is expended on blacks that whites in the older age cohorts $(80+)$.

\section{DISCUSSION}

Payment differences on the basis of gender, race, and area income generally narrow in the last 3 years of life. Differences on the basis of age persist; however, the direction of the difference changes in the last year of life, where expenditures on older cohorts decline relative to the youngest cohort. This pattern of findings on the basis of age in the last year of life is consistent with other study findings. ${ }^{27,35}$
This study is the first population-based study to identify a set of circumstances in which overall investments in health care are not substantially different by race, area income, and gender. Exploration of how these findings arise might help efforts to reduce widely found differences in other populations. Several possibilities might explain the absence of serious differences by race, gender, or area income in the last year of life. Perhaps the combination of nearly universal Medicare coverage for the elderly and having serious illnesses in the last year of life overcomes some of the usual barriers to health care. ${ }^{36,37}$ Differences in aggregate expenditures might also narrow if services are mostly supportive or they are approaching a maximum feasible utilization. Mean Medicare expenditures in the last year of life $(\$ 24,000)$ vary little by principal diagnosis or cause of death. ${ }^{38}$ Perhaps on average, what service health care providers can give during a year of serious illness effectively reaches a "saturation point." Or perhaps the typical patient becomes sick enough to make high-cost treatments inappropriate, in which case there are fewer high-cost treatments that might create evidence of disparities. ${ }^{39}$ Discerning the underlying cause of these findings could improve the understanding of differences in spending and utilization generally, as well as the understanding of payment and organization of care for those approaching the end of life specifically.

While private supplemental insurance and even Medicaid can positively influence total health care expenditures among healthy beneficiaries (reducing the amount paid 


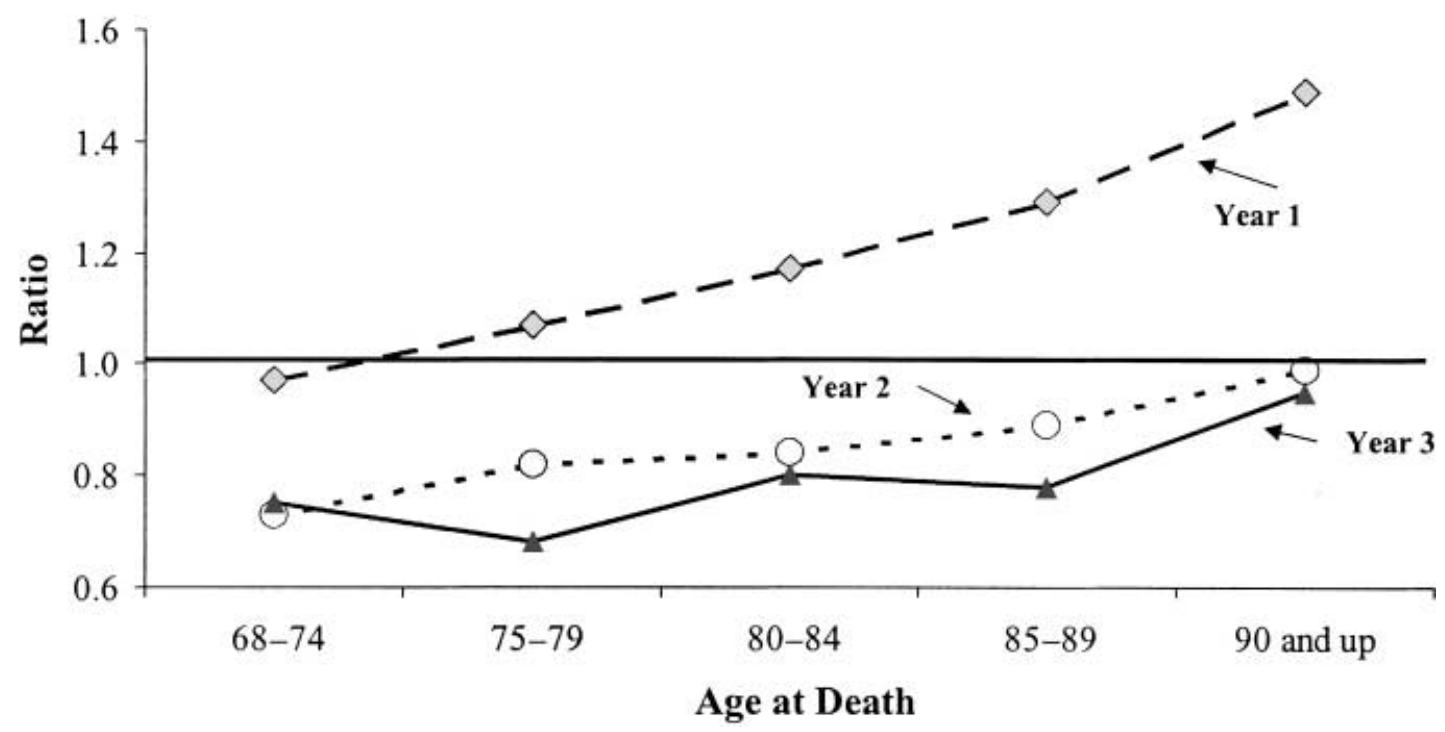

FIGURE 3. Ratio of regression-adjusted mean Medicare expenditures for blacks as compared to whites in the last 3 years of life, by age at death. ${ }^{*}$

* Regression-adjusted means were calculated for each beneficiary characteristic, controlling for other characteristics. Ratios calculated by dividing mean expenditures for blacks by mean expenditures for whites within each age cohort. The bar in the figure is set at a ratio of 1.0, reflecting no difference in expenditures.

${ }^{\dagger}$ Ratios for blacks versus whites are statistically significant at $P<.01$, with the exception of the ratio for those age 68 to 74 in the last year of life ( $95 \% \mathrm{Cl}, 0.94$ to 1.01), age 75 to 79 in the last year of life ( $95 \% \mathrm{Cl}, 1.00$ to 1.14), age 85 to 89 in the second year before death $(95 \% \mathrm{Cl}, 0.77$ to 1.00$)$, age $90+$ in the second year before death $(95 \% \mathrm{Cl}, 0.86$ to 1.11 ), and age $90+$ in the third year before death $(95 \% \mathrm{Cl}, 0.75$ to 1.09$)$.

out-of-pocket, thus reducing barriers to care), ${ }^{40}$ there is some evidence to suggest that this relationship is weakened among those with significant illness and disability. ${ }^{41}$ Furthermore, while hospice use varies nationally, ${ }^{42}$ recent analyses suggest that hospice care does not reduce total expenditures for most users. ${ }^{43}$ Blacks are less likely than whites to have advance directives, suggesting their expenditures would be higher at the end of life. ${ }^{44}$ However, advance directives may have little influence, ${ }^{45}$ in part because many are not implemented or are not decisive in the situation. ${ }^{46-48}$

Our analyses have several limitations. Although the study sample is not substantially different from the larger Medicare decedent population, the findings cannot be generalized to other populations (e.g., younger decedent populations, decedents in Medicare managed care, and populations not covered by Medicare). We addressed differences in mean expenditures across groups; however, there is great within-group variation in expenditures. Further research could explain how high-cost cases influence differences in total expenditures. This study employed ZIP code level data on income, so we cannot examine possible associations between individual income and Medicare expenditures. ${ }^{29,30}$ Subsequent analyses might use survey data such as the Medicare Current Beneficiary Survey to study the association between individual-level income and Medicare expenditures data. Finally, a small proportion of the sample has zero or very small expenditures, which could be accurate or could arise from billing mistakes or accessing care not covered by Medicare (i.e., Veterans'
Health Administration). We are unable to distinguish among those reasons for zero and low expenditures in our sample, which could have an important influence on our findings.

Our analyses have focused on differences in aggregate expenditures. Further analyses could illuminate the composition of services received by various groups. Furthermore, our data do not reflect all health care expenditures. Differences by age in the last year of life might disappear or even reverse if the data included nursing facility costs. ${ }^{49}$ Our findings also do not address variation in quality of care received at the end of life. Previously identified poor quality care near death $^{38,48,50}$ might correlate with patient characteristics.

The conclusion drawn from this paper-that differences in Medicare expenditures by gender, race, and area income become small or disappear in the last year of lifegreatly differs from previously cited reports of differences in health care utilization and expenditures at other points along the life course. Policy should not assume that gender, race, and area income differences persist at the end of life; however, considerable disparities may yet exist in the array of services accessed or the quality of end of life care. Additional research should yield insights as to why the differences observed farther from death narrow in the last year and as to whether these patterns occur in other cohorts at the end of life.

The authors thank Renee Labor and Lisa Spear for their assistance in producing this paper. 


\section{REFERENCES}

1. Murphy SL. Deaths: final data for 1998. Natl Vital Stat Rep. 2000;48:1-105.

2. Medicare Payment Advisory Commission (Medpac). Improving care at the end of life. In: Report to the Congress: Selected Medicare Issues. Washington, DC; 1999:117-32.

3. Lubitz JD, Riley GF. Trends in Medicare payments in the last year of life. N Engl J Med. 1993;328:1092-6.

4. Smedley BD, Stith AY, Nelson AR. eds. Unequal Treatment: Confronting Racial and Ethnic Disparities in Health Care. Washington, DC: National Academy Press; 2002.

5. Council on Ethical and Judicial Affairs, American Medical Association. Gender disparities in clinical decision making. JAMA. 1991; 266:559-62.

6. Fremont AM, Bird CE. Social and psychological factors, physiological processes, and physical health. In: Bird CE, Conrad P, Fremont AM, eds. Handbook of Medical Sociology. Upper Saddle River, NJ: Prentice Hall; 2000: 334-52.

7. Fiscella K, Franks P, Gold MR, Clancy CM. Inequality in quality: addressing socioeconomic, racial, and ethnic disparities in health care. JAMA. 2000;283:2579-84.

8. Rieker PP, Bird CE. Sociological explanations of gender differences in mental and physical health. In: Bird CE, Conrad P, Fremont AM, eds. Handbook of Medical Sociology. Upper Saddle River, NJ: Prentice Hall; 2000: 98-113.

9. Weinick RM, Zuvekas SH, Cohen JW. Racial and ethnic differences in access to and use of health care services, 1977-96. Med Care Res Rev. 2000;57(suppl 1):36-54.

10. Bach PB, Cramer LD, Warren JL, Begg CB. Racial differences in the treatment of early-stage lung cancer. N Engl J Med. 1999; 341:1198-205.

11. Dunlop DD, Manheim LM, Song J, Chang RW. Gender and ethnic/ racial disparities in health care utilization among older adults. J Gerontol B Psychol Sci Soc Sci. 2002;57:S221-S233.

12. Garg PP, Diener-West M, Powe NR. Income-based disparities in outcomes for patients with chronic kidney disease. Semin Nephrol. 2001;21:377-85.

13. Gornick ME, Eggers PW, Reilly TW, et al. Effects of race and income on mortality and use of services among Medicare beneficiaries. $\mathrm{N}$ Engl J Med. 1996;335:791-9.

14. Harada ND, Chun A, Chiu V, Pakalniskis A. Patterns of rehabilitation utilization after hip fracture in acute hospitals and skilled nursing facilities. Med Care. 2000;38:1119-30.

15. Schneider EC, Leape LL, Weissman JS, Piana RN, Gatsonis C, Epstein AM. Racial differences in cardiac revascularization rates: Does 'overuse' explain higher rates among white patients? Ann Intern Med. 2001;135:328-37.

16. Schulman KA, Berlin JA, Harless W, et al. The effect of race and sex on physicians' recommendations for cardiac catheterization. N Engl J Med. 1999;340:618-26.

17. Weitzman S, Cooper L, Chambless L, et al. Gender, racial, and geographic differences in the performance of cardiac diagnostic and therapeutic procedures for hospitalized acute myocardial infarction in four states. Am J Cardiol. 1997;79:722-6.

18. Schwartz LM, Fisher ES, Tosteson NA, et al. Treatment and health outcomes of women and men in a cohort with coronary artery disease. Arch Intern Med. 1997;157:1545-51.

19. Philbin EF, Disalvo TG. Managed care for congestive heart failure. Influence of payer status on process of care, resource utilization, and short-term outcomes. Am Heart J. 1998; 136:55361.

20. Escarce JJ. Medicare patients' use of overpriced procedures before and after the Omnibus Budget Reconciliation Act of 1987. Am J Public Health. 1993;83:349-55.

21. Ayanian JZ, Weissman JS, Chasan-Taber S, Epstein AM. Quality of care by race and gender for congestive heart failure and pneumonia. Med Care. 1999;37:1260-9.
22. East MA, Peterson ED. Understanding racial differences in cardiovascular care and outcomes: issues for the new millennium. Am Heart J. 2000;139:764-6.

23. Lee AJ, Baker CS, Gehlbach S, Hosmer DW, Reti M. Do black elderly Medicare patients receive fewer services? An analysis of procedure use for selected patient conditions. Med Care Res Rev. 1998; 55:314-33.

24. Riley GF, Lubitz JD. Longitudinal patterns of Medicare use by cause of death. Health Care Financ Rev. 1989;11:1-12.

25. Riley G, Lubitz J, Prihoda R, Rabey E. The use and costs of Medicare services by cause of death. Inquiry. 1987;24:233-44.

26. Lubitz J, Beebe J, Baker C. Longevity and Medicare expenditures. N Engl J Med. 1995;332:999-1003.

27. Levinsky NG, Yu W, Ash A, et al. Influence of age on Medicare expenditures and medical care in the last year of life. JAMA. 2001;286:1349-55.

28. Perls TT, Wood ER. Acute care costs of the oldest old: they cost less, their care intensity is less, and they go to nonteaching hospitals. Arch Intern Med. 1996;156:754-60.

29. Geronimus AT, Bound J. Use of census-based aggregate variables to proxy for socioeconomic group: evidence from national samples. Am J Epidemiol. 1998;148:475-86.

30. Krieger N, Williams DR, Moss NE. Measuring social class in US public health research: concepts, methodologies, and guidelines. Annu Rev Public Health. 1997;18:341-78.

31. Gelfi LM, Parker TS. A county-level measure of urban influence. Rural Dev Perspectives. 1995; 12:32-41.

32. Charlson ME, Pompei P, Ales KL, Mackenzie CR. A new method of classifying prognostic comorbidity in longitudinal studies: development and validation. J Chronic Dis. 1987;40:373-83.

33. SAS Institute Inc. Cary, NC; 1999.

34. Duan N. Smearing estimate: a nonparametric retransformation method. J Am Stat Assoc. 1983;78:605-10.

35. Bird CE, Shugarman LR, Lynn J. Age and gender differences in health care utilization and spending for Medicare beneficiaries in their last years of life. J Palliat Med. 2002;5:705-12.

36. Laforce FM, Wussow J. Chronic Illness in America: Overcoming Barriers to Building Systems of Care. Lawrenceville, NJ: Center for Health Care Strategies, Inc; 2001.

37. Crawley L, Payne R, Bolden J, et al. Palliative and end-of-life care in the African American community. JAMA. 2000;284:2518-21.

38. Hogan C, Lunney J, Gabel J, Lynn J. Medicare beneficiaries' costs of care in the last year of life. Health Aff (Millwood). 2001;20:188-95.

39. Hamel MB, Teno JM, Goldman L, et al. Patient age and decisions to withhold life-sustaining treatments from seriously ill, hospitalized adults. SUPPORT Investigators. Study to Understand Prognoses and Preferences for Outcomes and Risks of Treatment. Ann Intern Med. 1999; 130:116-25.

40. Khandker RK, Mccormack LA. Medicare spending by beneficiaries with various types of supplemental insurance. Med Care Res Rev. 1999;56:137-55.

41. Remler DK, Atherly AJ. Health status and heterogeneity of cost-sharing responsiveness: how do sick people respond to costsharing? Health Econ. 2003;12:269-80.

42. Virnig BA, Kind S, Mcbean M, Fisher E. Geographic variation in hospice use prior to death. J Am Geriatr Soc. 2000;48:111725.

43. Campbell DE, Lynn J, Louis TA, Shugarman LR. Hospice and medicare expenditures. Ann Intern Med. 2004;17:In press.

44. Blackhall LJ, Frank G, Murphy ST, et al. Ethnicity and attitudes towards life sustaining technology. Soc Sci Med. 1999;48:1779-89.

45. Angelos P, Johnston C. Advance directive use among patients undergoing selected high-risk surgical procedures. Qual Manag Health Care. 1999;7:1-3.

46. Coppola KM, Ditto PH, Danks JH, Smucker WD. Accuracy of primary care and hospital-based physicians' predictions of elderly outpatients' treatment preferences with and without advance directives. Arch Intern Med. 2001;161:431-40. 
47. Ditto PH, Danks JH, Smucker WD, et al. Advance directives as acts of communication: a randomized controlled trial. Arch Intern Med. 2001;161:421-30.

48. The SUPPORT Principal Investigators. A controlled trial to improve care for seriously ill hospitalized patients. The Study to Understand Prognoses and Preferences for Outcomes and Risks of Treatments (SUPPORT). JAMA. 1995;274:1591-8.
49. Scitovsky AA. Medical care in the last twelve months of life: the relation between age, functional status, and medical care expenditures. Milbank Q. 1988;66:640-60.

50. Bernabei R, Gambassi G, Lapane K, et al. Management of pain in elderly patients with cancer. SAGE Study Group. Systematic Assessment of Geriatric Drug Use via Epidemiology. JAMA. 1998; 279:1877-82. 